\title{
Predictors of Left Ventricular Dysfunction in Patients with First Acute Anterior Myocardial Infarction Undergoing Primary Percutaneous Coronary Intervention
}

\author{
MOHAMED H. SENARA, M.Sc.; SEHAM F. BADR, M.D.; EHAB A. AL-GENDY, M.D. and \\ MOHAMED N. HUSSIEN, M.D. \\ The Department of Cardiovascular Medicine, Faculty of Medicine, Tanta University, Tanta, Egypt
}

\begin{abstract}
Background: LV dysfunction after acute MI is the most important factor affecting morbidity and mortality. Any effort should be made to minimize it.

Aim of the Study: To evaluate the effect of clinical and angiographic variables on LV systolic function in patients with first acute anterior MI undergoing primary PCI.

Patients and Methods: A prospective observational study conducted from October 2016 to June 2017, at the Cardiovascular Medicine Department, Tanta University Hospitals in Gharbia Governorate, Egypt. The study enrolled 100 consecutive adult patients of both genders who were diagnosed with definite first acute anterior MI within 12 hours from the time of symptoms onset and were treated by primary PCI. Clinical and angiographic data were collected prospectively. Clinical outcome (death, major cardiovascular event) were evaluated during hospitalization. Patients were divided into three groups by degree of LV dysfunction, normal-mild (EF $>50 \%$ ), moderate $(\mathrm{EF}=40-50 \%)$ and severe $(\mathrm{EF}<40 \%)$ and compared for clinical, angiographic and procedural variables.
\end{abstract}

Results: On statistical analysis between studied groups, the principal finding of this study was that depressed LV function in patients with first acute anterior MI was associated with longer time to door $(r=0.560, p=<0.001)$ and door to balloon $(r=0.378, p=<0.001)$ times, higher CKMB level $(r=0.565, p=<0.001)$, renal impairment defined as creatinine clearance $<60 \mathrm{~mL} / \mathrm{min}$ ( $p=0.013$ ), peripheral vascular disease $(p=0.013)$, low TIMI flow grade before and after angioplasty $(r=0.347, p=<0.001)$, low myocardial blush grade $(r=0.347$, $p=<0.001$ ). Regarding in-hospital mortality and major cardiovascular events defined as recurrent myocardial infarction, repeat coronary revascularization of the target lesion, and heart failure, was higher in Group III.

Conclusion: Degree of LV dysfunction following first acute anterior MI can be identified by clinical and angiographic variables that are readily available at the time of initial assessment. The principal finding of this study is that abnormal LV systolic function after first acute anterior MI can be predicted by longer door to balloon time and larger infarction

Correspondence to: Dr. Mohamed H. Senara, The Department of Cardiovascular Medicine, Faculty of Medicine, Tanta University, Tanta, Egypt size as assessed by CKMB levels. Renal impairment, peripheral vascular disease, multi-vessel disease and low TIMI flow grade before and after angioplasty are associated with depressed LV function in patients with first acute anterior MI.

Key Words: LV dysfunction - First acute anterior MI - Primary percutaneous coronary intervention.

\section{Introduction}

WORLDWIDE, Coronary Artery Disease (CAD) is the single most frequent cause of death. Over seven million people every year die from CAD, accounting for $12.8 \%$ of all deaths [1].

LV dysfunction after acute MI is the most important factor affecting morbidity and mortality. Every effort should be made to minimize it. Prompt restoration of myocardial blood flow is essential to optimize myocardial salvage and to reduce mortality [2].

A decision must be made as soon as possible as to whether reperfusion will be achieved with fibrinolytic agents or primary PCI. Delays in the timely implementation of reperfusion therapy are key issues in the management of MI, since the greatest benefit gained from reperfusion therapy occurs within the first 2-3 hours of symptom onset $[3,4]$.

The aim is to evaluate the effect of clinical and angiographic variables on LV systolic function.

\section{Patients and Methods}

This study was conducted prospectively on 100 patients with first acute anterior MI who were treated with primary PCI at the Department of Cardiovascular Medicine, Tanta University Hospital at the period between October 2016 and June 2017. 
Inclusion criteria were: Confirmed first acute anterior MI in patients presented with typical angina pain started within the last 12 hours and ST-segment elevation $\geq 1 \mathrm{~mm}$ in at least two contiguous leads or new onset left bundle branch block with troponin elevation [5]

Exclusion criteria were: (1) Patient refusal. (2) Patient who received fibrinolytic therapy prior to PCI. (3) Prior MI. (4) Prior PCI. (5) Patients with cardiogenic shock. (6) Prior coronary artery bypass surgery.

Patients with first anterior MI who underwent emergency PCI were prospectively observed to evaluate the effect of clinical and angiographic variables on LV systolic function. The study sample was subjected to the following:

An informed consent, history taking with special emphasis on presence of risk factors for ischemia such as (family history of premature coronary disease, systemic hypertension, diabetes mellitus, dyslipidemia), clinical examination, twelve leads ECG, routine laboratory investigations (kidney function test, liver function test, random blood sugar, cholesterol, triglyceride, HDL, LDL, INR and complete blood picture), primary angioplasty and standard 2D and Doppler echocardiogram was obtained in all patients within 24 .

All patients were subjected to primary PCI for the Infarct Related Artery (IRA). All patients received aspirin (loading dose of $150-300 \mathrm{mg}$ orally) and clopidogrel (loading dose of $600 \mathrm{mg}$ orally) or ticagrelor (loading dose of $180 \mathrm{mg}$ orally) and unfractionated heparin $70-100 \mathrm{U} / \mathrm{kg}$ i.v bolus when no GPIIb/IIIa inhibitor was planned and 50-60 U/kg i.v bolus with GP IIb/IIIa inhibitors before the procedure. The decision to administer glycoprotein IIb/IIIa inhibitors was made by the interventional cardiologist.

Angiographic films were reviewed and interpreted by an experienced interventional cardiologist as regard to TIMI flow before and after revascularization, myocardial blush grade, glycoprotein IIb/IIIa inhibitors use, multivessel disease, noslow reflow, contrast volume, fluoroscopy time, stenting, using DES and thrombus aspiration.

Standard 2D and Doppler echocardiogram was obtained in all patients within 24 hours of presentation using a commercially available machine in our department (Vivid 7, GE Medical System, Horten, Norway) with a $3.5-\mathrm{MHz}$ transducer). To evaluate ejection fraction an experienced cardiologist who was blinded to the clinical outcome performed the analysis. LVEF was calculated by M-Mode and 2D Simpson's method.

On the basis of the findings, the patients were divided into three groups of LV dysfunction, normal-mild (EF $>50 \%)$, moderate $(\mathrm{EF}=40-50 \%)$ and severe $(\mathrm{EF}<40 \%)$ to evaluate effect of clinical variables [age, sex, diabetes, hyperlipidemia, hypertension, smoking, peripheral vascular disease, prior stroke, renal impairment, blood pressure, Killip class, symptoms to door time (hrs.) and door to balloon time (hrs.)] and angiographic variables [TIMI flow before PCI, TIMI flow after PCI, myocardial blush grade, glycoprotein IIb/IIIa inhibitors use, multivessel disease, no/slow reflow, contrast media quantity, fluoroscopy time, stenting, using DES and thrombus aspiration] on LV systolic function.

Follow-up of all patients included in the study as regard in hospital mortality and major adverse cardiovascular events defined as recurrent acute MI, repeat coronary revascularization of the target lesion, and heart failure.

Statistical presentation and analysis of the present study was conducted, using the mean, standard deviation and chi-square test by SPSS V.20. Numerical data was presented as mean and Standard Deviation (SD) and categorical data was presented as number and percentage. Chi-squared test was used for statistical analysis. When the chisquared test was not appropriate, the likelihood ratio test was applied. The level of significance was adopted at $p<0.05$.

\section{Results}

To evaluate the effect of clinical and angiographic variables on LV systolic function patients were divided into three groups of $\mathrm{LV}$ dysfunction, Group I normal-mild (EF $>50 \%$ ), Group II moderate $(\mathrm{EF}=40-50 \%)$, Group III severe (EF <40\%).

As regard demographic data, there was no statistical significant difference between the three groups (Table 1).

As regard risk factors, there were no statistical significant difference between the three groups as regard history of diabetes, hypertension, smoking, prior stroke, hyperlipidemia, blood pressure readings at time of admission and Killip class. There were significant differences between studied groups as regard history of peripheral vascular disease, renal impairment (CRCL $<60 \mathrm{ml} / \mathrm{min}$ ), symptoms to door time and door to balloon time (Table 2). 
As regard routine laboratory investigations, there was significant difference between groups as regard CKMB level (Table 3).

As regard angiographic variables, there were statistical significant differences between studied groups as regard TIMI flow and myocardial blush grade after revascularization (Table 4).

Correlation between EF (\%) and different parameters in total sample show moderate positive correlation between LV systolic function and TIMI flow after PCI and myocardial blush grade. There was strong negative correlation between $\mathrm{EF} \%$ and time to door time (hr.) and CKMB level and moderate correlation with door to balloon time (hr.). (Table 5) Figs. $(1,2)$.
Regarding in-hospital mortality, it was found that mortality risks increase across studied groups. $0 \%$ in Group I (mild LV dysfunction), while 4\% in Group II (moderate LV dysfunction); Group III (severe LV dysfunction) showed 14\% mortalities. There was significant difference regarding mortality among studied groups, $(p$-value $<0.001)$ (Table 6).

Regarding in-hospital MACE (major adverse cardiac events) defined as recurrent acute MI, repeat coronary revascularization of the target lesion, and heart failure it was found that adverse outcomes increase across groups. In Group I, 7\%, $15 \%$ in Group II, while in group III $28 \%$. There was significant difference among groups with ( $p$ value $<0.001$ ) (Table 6).

Table (1): Comparison between the different studied groups according to demographic data.

\begin{tabular}{lllll}
\hline Demographic data & $\begin{array}{c}\text { Group I } \\
(\mathrm{n}=26)\end{array}$ & $\begin{array}{c}\text { Group II } \\
(\mathrm{n}=53)\end{array}$ & $\begin{array}{c}\text { Group III } \\
(\mathrm{n}=21)\end{array}$ & $p$ \\
\hline Age (years) (Mean $\pm \mathrm{SD})$ & $56.23 \pm 13.24$ & $61.75 \pm 11.65$ & $56.57 \pm 11.80$ & 0.091 \\
Male gender \% & 50 & 45.3 & 42.9 & 0.877 \\
\hline
\end{tabular}

Table (2): Comparison between the different studied groups according to clinical variables.

\begin{tabular}{lllll}
\hline Clinical variables & Group I & Group II & Group III & $p$ \\
\hline Diabetes mellitus \% & 46.2 & 41.5 & 57.1 & 0.477 \\
Hypertension \% & 47 & 42 & 52.4 & 0.692 \\
Smoking \% & 53.8 & 49.1 & 52.4 & 0.914 \\
Peripheral vascular disease \% & 4.2 & 7 & 32 & $0.015^{*}$ \\
Prior Stroke \% & 3.4 & 5.2 & 4.8 & 1.000 \\
Hyperlipidemia \% & 42.3 & 39.6 & 52.4 & 0.605 \\
Renal impairment (CRCL $<60 \mathrm{ml} / \mathrm{min}) \%$ & 3.8 & 5.7 & 28.6 & $0.013^{*}$ \\
Symptoms to door time (hrs.) (Mean \pm SD) & $1.01 \pm 0.49$ & $2.02 \pm 1.31$ & $6.94 \pm 4.80$ & $<0.001^{*}$ \\
Door to balloon time (hrs.) $(\mathrm{Mean} \pm \mathrm{SD})$ & $0.73 \pm 0.24$ & $1.51 \pm 0.60$ & $1.45 \pm 0.62$ & $<0.001^{*}$ \\
Systolic blood pressure (mmHg)(Mean $\pm \mathrm{SD})$ & $136 \pm 26$ & $136 \pm 22$ & $126 \pm 20$ & 0.7 \\
Diastolic blood pressure (mmHg) (Mean $\pm \mathrm{SD})$ & $77 \pm 13$ & $80 \pm 10$ & $74 \pm 10$ & 0.07 \\
Killip class $>$ I\% & 3.2 & 7.9 & 19.0 & 0.237 \\
\hline
\end{tabular}

Table (3): Comparison between the different studied groups according to laboratory data.

\begin{tabular}{lllll}
\hline Laboratory investigations & \multicolumn{1}{c}{$\begin{array}{c}\text { Group I } \\
(\mathrm{n}=26)\end{array}$} & $\begin{array}{c}\text { Group II } \\
(\mathrm{n}=53)\end{array}$ & $\begin{array}{c}\text { Group III } \\
(\mathrm{n}=21)\end{array}$ & $p$ \\
\hline CKMB (mean $\pm \mathrm{SD})$ & $37.19 \pm 10.57$ & $72.68 \pm 43.02$ & $150.0 \pm 59.15$ & $<0.001^{*}$ \\
Hemoglobin (mean $\pm \mathrm{SD})$ & $11.48 \pm 1.34$ & $11.51 \pm 1.20$ & $11.17 \pm 1.10$ & 0.535 \\
WBCS (mean $\pm \mathrm{SD})$ & $5.27 \pm 1.61$ & $5.39 \pm 1.96$ & $5.21 \pm 1.78$ & 0.957 \\
Platelets (mean $\pm \mathrm{SD})$ & $243.46 \pm 95.54$ & $247.30 \pm 93.76$ & $250.24 \pm 93.49$ & 0.937 \\
Elevated liver enzymes \% & 3.8 & 3.8 & 4.8 & 1.000 \\
Random blood sugar (mean $\pm \mathrm{SD})$ & $151.58 \pm 83.46$ & $193.38 \pm 105.15$ & $206.19 \pm 98.97$ & 0.066 \\
INR (mean $\pm \mathrm{SD})$ & $1.10 \pm 0.14$ & $1.09 \pm 0.11$ & $1.10 \pm 0.12$ & 0.968 \\
\hline
\end{tabular}


Table (4): Comparison between the studied groups according to angiographic variables.

\begin{tabular}{lllll}
\hline Angiographic variables & $\begin{array}{c}\text { Group I } \\
(\mathrm{n}=26)\end{array}$ & $\begin{array}{c}\text { Group II } \\
(\mathrm{n}=53)\end{array}$ & $\begin{array}{c}\text { Group III } \\
(\mathrm{n}=21)\end{array}$ & $p$ \\
\hline TIMI flow before revascularization (0-I) \% & 57.7 & 66.0 & 66.7 & 0.737 \\
TIMI flow after revascularization (III)\% & 100.0 & 94.3 & 61.9 & $<0.001$ \\
Myocardial blush grade III \% & 100.0 & 91 & 63 & $<0.001$ \\
Glycoprotein IIb/IIIa inhibitors use \% & 76.9 & 79.2 & 81.0 & 0.943 \\
Multivessel disease \% & 12.2 & 14.9 & 19.0 & 1.000 \\
No-slow reflow \% & 3.8 & 7.5 & 19 & 0.237 \\
Contrast volume ml (mean \pm SD) & $181 \pm 66.49$ & $181 \pm 68.25$ & $176 \pm 55.15$ & 0.997 \\
Fluoroscopy time (min) & $14 \pm 10$ & $17 \pm 8$ & $16 \pm 7$ & 0.372 \\
Stenting \% & 98.2 & 94.5 & 88.0 & 0.257 \\
Drug eluting stent \% & 92 & 95.6 & 93.4 & 0.237 \\
Thrombus aspiration \% & 3 & 5.9 & 4.2 & 1.000 \\
\hline
\end{tabular}

Table (5): Correlation between EF (\%) and different parameters in total sample $(\mathrm{n}=100)$.

\begin{tabular}{lcc}
\hline & \multicolumn{2}{c}{ EF (\%) } \\
\cline { 2 - 3 } & $r$ & $p$ \\
\hline Time to door (hr.) & $-0.560^{*}$ & $<0.001^{*}$ \\
Door to balloon (hr.) & $-0.378^{*}$ & $<0.001^{*}$ \\
CKMB & $-0.565^{*}$ & $<0.001^{*}$ \\
TIMI flow after PCI & $0.347^{*}$ & $<0.001^{*}$ \\
MBG & $0.347^{*}$ & $<0.001^{*}$ \\
\hline
\end{tabular}

Table (6): In-hospital outcomes among studied groups.

\begin{tabular}{|c|c|c|c|c|c|c|}
\hline & \multicolumn{2}{|c|}{$\begin{array}{l}\text { Normal } \\
\text { mild } \\
(n=26)\end{array}$} & \multicolumn{2}{|c|}{$\begin{array}{l}\text { Moderate } \\
\quad(\mathrm{n}=53)\end{array}$} & $\begin{array}{l}\text { Severe } \\
(n=21)\end{array}$ & \multirow[t]{2}{*}{$p$} \\
\hline & No. & $\%$ & No. & $\%$ & No. \% & \\
\hline In hospital mortality & 0 & 0 & 2 & 4 & $3 \quad 14$ & $<0.001$ \\
\hline In hospital MACE & 2 & 7 & 8 & 15 & 628 & $<0.001$ \\
\hline
\end{tabular}

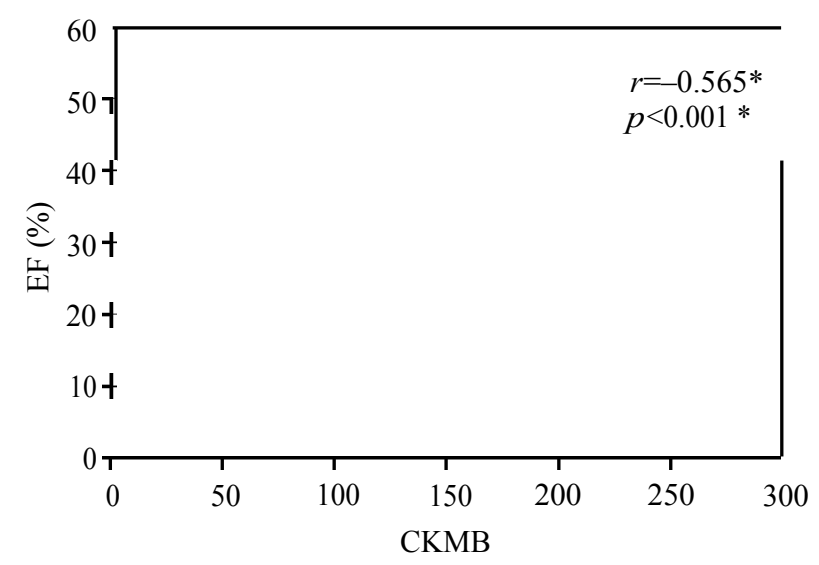

Fig. (1): Correlation between EF (\%) and CKMB level in total sample $(n=100)$.

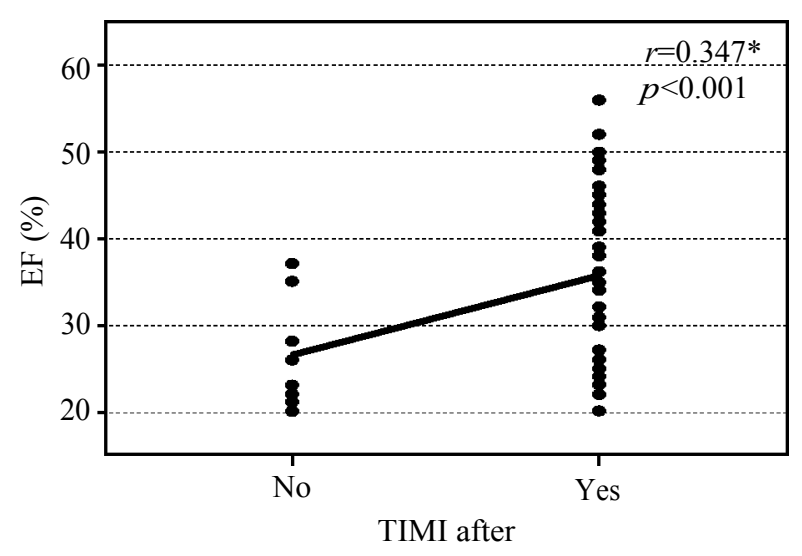

Fig. (2): Correlation between EF (\%) and TIMI flow after revascularization in total sample $(n=100)$.

\section{Discussion}

In the present study, there was no statistically significant difference between the three groups as regard age and gender as predictors of LVEF.

As regard risk factors, DM, systemic HTN, smoking and hyperlipidemia there were no statistically significant difference between the three groups.

In contrast to the present study, De Luca $\mathrm{G}$ et al., [6], in their study which was conducted on 1662 patients with STEMI who underwent primary PCI to study the impact of advanced age on myocardial perfusion, distal embolization, and mortality reported that elderly patients complicated with higher incidence of hypertension and diabetes, were more likely to have severe LV dysfunction with higher mortality after STEMI.

In the present study, there were no significant differences among the three groups with regard to past history of stroke $(p$-value $=1.000)$. 
Peripheral vascular disease correlates with poor outcome and is associated with adverse outcome in patients with acute coronary syndrome, due to the bigger burden of atherosclerosis (88) and chronic CAD. In the present study, patients with severe LV dysfunction were more likely to have peripheral vascular disease $(p=0.013)$ than those with mild or moderate LV dysfunction.

Cotter et al., [7], in their study which examined the effect of cerebrovascular and PVD on the outcome of 10,281 patients with acute coronary syndromes enrolled in (OPUS-TIMI) 16 trial of the oral glycoprotein IIb/IIIa antagonist Orbofiban plus aspirin versus aspirin alone. Cotter et al., [7], found that patients with acute coronary syndrome and other vascular disease, including PVD, cerebrovascular accident, and transient ischemic attack, had a high likelihood of decreased EF.

In the present study, patients with severe LV dysfunction were more likely to have pre-PCI renal impairment (creatinine clearance $<60 \mathrm{~mL} / \mathrm{min}$ calculated by Cockcroft-Gault equation (83)) ( $p$-value $=0.013)$ than those with mild or moderate LV dysfunction. Similarly, Sabroe et al., [8], found that patients with renal impairment undergoing primary PCI were more likely to have a reduced LVEF; however, this was not the primary endpoint of their study. The study cohort consisted of 4,116 patients of whom $898(21.8 \%)$ had renal impairment (that was defined as creatinine clearance $(\mathrm{CrCl})<60$ $\mathrm{mL} / \mathrm{min})$ and 3,218 (78.2\%) had a $\mathrm{CrCl}>60$ $\mathrm{mL} / \mathrm{min}$. Compared to patients without renal impairment, patients with renal impairment were older, more often female and more likely to have diabetes mellitus, hypertension and to present with a higher Killip class. The conclusion of that study was that in unselected STEMI patients treated with primary PCI, moderate and severe renal impairment were associated with increased risk of mortality.

In the present study, as regard to symptoms to door time that was defined as the time from the symptoms onset to first medical contact, patients with severe LV dysfunction were more likely to have longer symptoms to door time $(p=<0.001)$ than those with mild or moderate LV dysfunction. Patients with moderate and severe LV dysfunction had a longer door to needle time as compared to patients with mild LV dysfunction ( $p$-value= $<0.001$ ). LV function decreased with an increase in door to needle time, however patients with moderate and severe LV dysfunction had nearly similar door to balloon time ( $p$-value $=0.748)$.
Similarly, Brodie et al., [9], in their study which was conducted on 1,352 patients with acute MI treated with primary angioplasty and were followed for up to 13 years, both acute and follow-up ejection fraction data were obtained at cardiac catheterization in 606 patients. Brodie et al., [9], concluded that, time to reperfusion, up to $2 \mathrm{~h}$, was important for survival and recovery of left ventricular function. After $2 \mathrm{~h}$, recovery of $\mathrm{LV}$ function is modest and survival is relatively independent of time to reperfusion.

Similarly, De Luca et al., [6] reported that longer time to treatment significantly impaired myocardial perfusion, which resulted in worse coronary microcirculation and higher mortality after STEMI.

In the present study, as regard blood pressure at time of admission, systolic and diastolic blood pressures were recorded in all patients, and there were no significant statistical differences among the three studied groups ( $p$-value $=0.7)$.

Roth D et al., [10], included consecutive patients treated for acute MI at their 2,200-bed tertiary care hospital from 1991 to 2009 into their cohort. Systolic, diastolic and pulse pressure on admission were analyzed as main predictors for 1-year mortality. It concluded that in acute myocardial infarction, admission blood pressure predicts long-term mortality in an inverse relation. With increasing admission blood pressure long-term mortality decreases. Low admission blood pressure should serve as a warning sign in patients with AMI.

In the present study, more advanced Killip class at presentation in the form of (S3 gallop, basal lung rales, jugular venous distention or overt pulmonary edema) was more likely to occur with severe LVEF ( $p$-value $=0.237)$. De Luca G et al., [6], reported that more advanced Killip class at presentation was associated with significantlly impaired myocardial perfusion, which resulted in worse coronary microcirculation and higher mortality after STEMI.

As regard to TIMI III flow before revascularization, in this study TIMI III flow at initial angiography was less likely to be present in patients with severe LV dysfunction. Similarly, Stone et al., [11], among 2507 patients enrolled in four PAMI (Primary Angioplasty in Myocardial Infarction) trials undergoing primary PTCA, spontaneous reperfusion (TIMI-III flow) was present in $16 \%$ at initial angiography. Compared with patients without TIMI-III flow, those with TIMI-III flow before PTCA had greater left ventricular ejection fraction and were less likely to present in heart failure. In 
the present study, TIMI III flow was less often to be achieved after PCI in patients with severe LV dysfunction. $61.9 \%$ in severe LV dysfunction (Group III), 94.3\% in patients with moderate dysfunction (Group II) and $100 \%$ in patients with mild LV dysfunction (Group I) ( $p$-value $=<0.001)$. Similarly, Chen et al., [12], they retrospectively analyzed the patients admitted with acute MI, who were treated successfully with emergency PCI. According to situation for cardiovascular events, patients were divided into 2 groups. The clinical factors were compared between the 2 groups. It concluded that Killip grade $>2$, TIMI flow after PCI $<2$, long door to balloon time are important predictors for inhospital cardiac events and LV dysfunction.

In the present study, myocardial blush grade III was less often to be achieved after PCI in patients with severe LV dysfunction; $63 \%$ in severe LV dysfunction (Group III), 91\% in patients with moderate dysfunction (Group II) and 100\% in patient with mild LV dysfunction (Group I) ( $p$ value $=<0.001)($ Table 4). Similarly, Farag EM et al., [13], included 232 STEMI patients treated with primary PCI. Echocardiography was done on the day of PCI and after six months. LV remodeling was defined as $>20 \%$ increase in the six-month Left Ventricular Ėnd-Diastolic Volume (LVEDV). It was found that longer symptom to door and symptom to balloon times and lower myocardial blush grade were associated with significantly lower initial EF.

In the present study, the use of Glycoprotein IIb/IIIa Inhibitors was according to decision of the operators. There were no significant differences among the three groups with regard to its use.

In the present study, multi-vessel disease was mainly associated with reduced LV function but without significant differences among the three groups $(p$-value $=1.000)$.

Similarly, Zhang-Wei Chen et al., [14] reported that age, time to hospital, multi-vessel stenosis significantly increased the risk of reduced LVEF.

In the present study, no-slow reflow was mainly associated with reduced LV function but without significant differences among the three groups ( $p$ value $=0.237$ ).

Similarly, Giustino et al., [15], 402 patients enrolled in the INFUSE-AMI trial with data on NYHA class at 30 days, 76 (18.9\%) had NYHA class $>2$. Independent correlates of 30-day NYHA class $>2$ were age, Killip class $>2$ at presentation, heart rate at presentation, intra-procedural no- reflow. This study reported that intra-procedural no-reflow was associated with reduced initial left ventricular ejection fraction.

As regard to contrast volume there were no significant differences among the three groups.

Prolonged fluoroscopy times during Percutaneous Coronary Intervention (PCI) reflect various factors including the complexity of the anatomical disease and patients treated operator skills and any acute procedural complications.

There were no significant differences among the three groups with regard to fluoroscopy time $(p$-value $=0.372)$.

Stenting was done in almost all cases, the decision of deferred stenting with only diagnostic angiography, PTCA or thrombus aspiration was done by operators in few cases due to highly thrombotic field.

Mentias et al., [16] reported that in patients undergoing primary PCI, deferred stent implantation does not appear to improve clinical outcomes. Future randomized trials are encouraged to identify the patient population who might benefit from a deferred stent implantation strategy (e.g., high thrombus burden). New ESC guidelines 2017 stated that routine use of thrombus aspiration and deferred stenting is not recommended (class III) [17].

Regarding in-hospital mortality, it was found that mortality risks increase across studied groups. $0 \%$ in Group I (mild LV dysfunction), while 4\% in Group II (moderate LV dysfunction); Group III (severe LV dysfunction) showed 14\% mortalities. There was significant difference regarding mortality among studied groups ( $p$-value $<0.001$ ) (Table 6 .

Regarding in-hospital MACE (major adverse cardiac events) defined as recurrent AMI, repeat coronary revascularization of the target lesion, and heart failure it was found that adverse outcomes increase across groups. In Group I, 7\%, $15 \%$ in Group II, while in Group III 28\%. There was significant difference among groups with ( $p$-value $<0.001$ ) (Table 6).

Bigger et al., [18] reported that patients with LVEF $<40 \%$ had a higher in-hospital mortality rate than those with LVEF $>40 \%$ (10\%-13\% vs. $2.3 \%$ $7.7 \%, p<0.001)$. Its principal was to evaluate relations between left ventricular dysfunction, ventricular arrhythmias and mortality after myocardial infarction. 


\section{Study limitations:}

The study had some limitations. This is a singlecenter experience and represents a limited number of patients.

LV function was assessed at the first 24 hours after acute MI, but depressed LV function in the first days/weeks after acute MI may be affected by stunning rather than permanent myocardial damage [19].

\section{Conclusion:}

Degree of LV dysfunction following first acute anterior MI can be identified by clinical and angiographic variables that are readily available at the time of initial assessment.

The principal finding of this study is that LV dysfunction after first acute anterior MI can be predicted by longer door to balloon time and larger infarction size as assessed by CKMB levels.

Renal impairment, peripheral vascular disease, multi-vessel disease and low TIMI flow grade before and after angioplasty are associated with depressed LV function in patients with first acute anterior MI.

\section{References}

1- WHO |fact sheat. WHO. World Health Organization; 2017. http://www.who.int/mediacentre/factsheets/fs317/en// (updated May 2017).

2- ANDERSON J.L., KARAGOUNIS L.A. and CALIFF R.M.: Metaanalysis of five reported studies on the relation of early coronary patency grades with mortality and outcomes after acute myocardial infarction. Am. J. Cardiol. Jul. 1; 78 (1): 1-8, 1996.

3- STEG P.G., JAMES S.K., ATAR D., BADANO L.P., LUNDQVIST C.B., BORGER M.A., et al.: ESC Guidelines for the management of acute myocardial infarction in patients presenting with ST-segment elevation: The Task Force on the management of ST-segment elevation acute myocardial infarction of the European Society of Cardiology (ESC). Eur. Heart J., Oct. 2; 33 (20): 2569619, 2012.

4- GERSHLICK A.H., BANNING A.P., MYAT A., VERHEUGT F.W.A. and GERSH B.J.: Reperfusion therapy for STEMI: Is there still a role for thrombolysis in the era of primary percutaneous coronary intervention? Lancet. Aug., 17; 382 (9892): 624-32, 20132.

5- TAYLOR J.: Third universal definition of myocardial infarction. Eur. Heart J., Oct. 2; 33 (20): 2503-9, 2012.

6- De LUCA G., VAN'T HOF A.W., HUBER K., GIBSON C.M., BELLANDI F., ARNTZ H.R., et al.: Impact of advanced age on myocardial perfusion, distal embolization, and mortality patients with ST-segment elevation myocardial infarction treated by primary angioplasty and glycoprotein IIb-IIIa inhibitors. Heart Vessels, 29 (1): 15$20,2014$.
7- COTTER G., CANNON C.P., McCABE C.H., MICHOWITZ Y., KALUSKI E., CHARLESWORTH A., et al.: Prior peripheral arterial disease and cerebrovascular disease are independent predictors of adverse outcome in patients with acute coronary syndromes: Are we doing enough? Results from the Orbofiban in Patients with Unstable Coronary Syndromes-Thrombolysi. Am. Heart J., Apr. 145 (4): 622-7, 2003.

8- SABROE J.E., THAYSSEN P., ANTONSEN L., HOU GAARD M., HANSEN K.N. and JENSEN L.O.: Impact of renal insufficiency on mortality in patients with STsegment elevation myocardial infarction treated with primary percutaneous coronary intervention. B.M.C. Cardiovasc. Disord., Feb. 7; 14: 15, 2014.

9- BRODIE B.R., STUCKEY T.D., WALL T.C., KISSLING G., HANSEN C.J., MUNCY D.B., et al.: Importance of time to reperfusion for 30-day and late survival and recovery of left ventricular function after primary angioplasty for acute myocardial infarction. J. Am. Coll. Cardiol., Nov. 32 (5): 1312-9, 1998.

10- ROTH D., VAN TULDER R., HEIDINGER B., HERKNER H., SCHREIBER W. and HAVEL C.: Admission blood pressure and 1-year mortality in acute myocardial infarction. Int. J. Clin. Pract., Aug. 69 (8): 812-9, 2015.

11- STONE G.W., COX D., GARCIA E., BRODIE B.R., MORICE M.C., GRIFFIN J., et al.: Normal Flow (TIMI3) Before Mechanical Reperfusion Therapy Is an Independent Determinant of Survival in Acute Myocardial Infarction Analysis From the Primary Angioplasty in Myocardial Infarction Trials. Circulation, 104: 636-41, 2001.

12- CHEN C., HUANG Y., ZHOU S. and FANG Z.: [Influencial factors for in-hospital patients with ST segment elevation myocardial infarction after emergency percutaneous coronary intervention. Zhong Da Xue Xue Bao Yi Xue Ban., Nov. 2841 (11): 1186-92, 2016.

13- FARAG E.M. and AL-DAYDAMONY M.M.: Symptomto-balloon time and myocardial blush grade are predictors of left ventricular remodelling after successful primary percutaneous coronary intervention. Cardiovasc. J. Afr., Jun 23; 28 (3): 186-90, 2017.

14- CHEN Z.W., YU Z.Q., YANG H.B., CHEN Y.H., QIAN J.Y., SHU X.H., et al.: Rapid predictors for the occurrence of reduced left ventricular ejection fraction between LAD and non-LAD related ST-elevation myocardial infarction. B.M.C. Cardiovasc. Disord., 16: 3, 2016.

15- GIUSTINO G., REDFORS B., BRENER S.J., KIRTANE A.J., GÉNÉREUX P., MAEHARA A., et al.: Correlates and prognostic impact of new-onset heart failure after ST-segment elevation myocardial infarction treated with primary percutaneous coronary intervention: Insights from the INFUSE-AMI trial. J.A.M.A., 307 (17): 181726, 2012.

16- MAHMOUD A.N., SAAD M. ELGENDY A.Y., MENTIAS A. and ELGENDY I.Y.: Deferred or immediate stent implantation for primary percutaneous coronary intervention: A meta-analysis of randomized trials. Catheterization and Cardiovascular Interventions Journal, Aug. 11, 145 (4): 622-7, 2017.

17- IBANEZ B., JAMES S., AGEWALL S., ANTUNES M.J., BUCCIARELLI-DUCCI C., BUENO $\mathrm{H}$., et al.: ESC 
Guidelines for the management of acute myocardial infarction in patients presenting with ST-segment elevation: The Task Force for the management of acute myocardial infarction in patients presenting with ST-segment elevation of the European Society of Cardiology (ESC). Eur. Heart J., 2018 Jan. 7; 39 (2): 119-77, 2017.
18-BIGGER J.T.: Relation between left ventricular dysfunction and ventricular arrhythmias after myocardial infarction. Am. J. Cardiol., Jan. 31; 57 (3): 8B-14B, 1986.

19- RAHIMTOOLA S.H.: The hibernating myocardium in ischaemia and congestive heart failure. Eur. Heart J., 14 (Suppl A): 22, 1993.

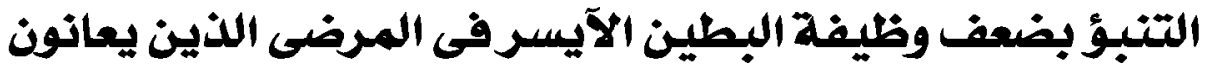

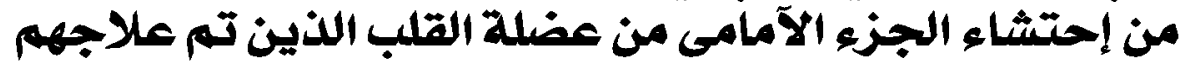 عن طريق قسطرة القلب العلاجية}

تم إجراء القسطرة القلبية العلاجية في قسم القلب بجامعة طنطا لعدد مئة من المرضى الذين يعانون من إحتشاء الجزء الآمامى لعضلة إلهاء

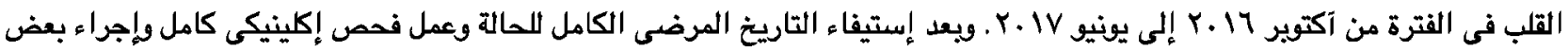

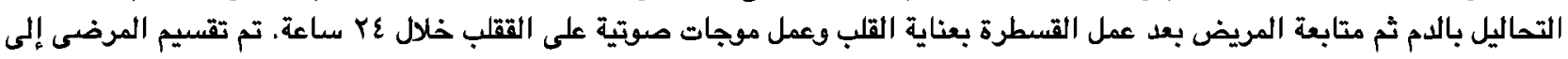
ثلاثة مجموعاث على حسب درجة إعتلال وظيفة البطين الآيسر.

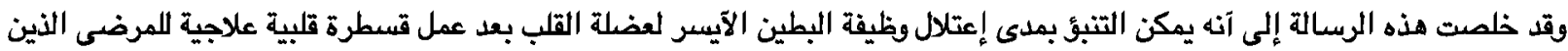

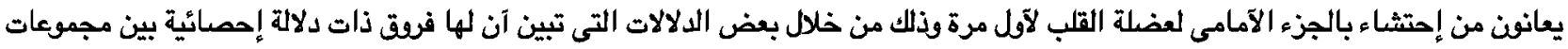

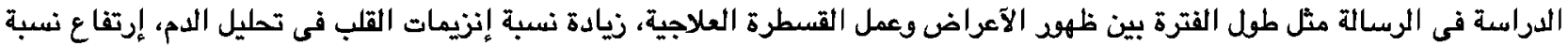

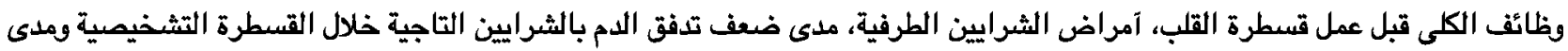

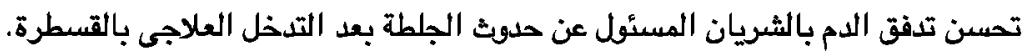

